The Problem of Non-Renewable Energy

Resources in the Production of Physical Capital

A. Perez-Barahona

Discussion Paper 2007-7

Département des Sciences Économiques

de l'Université catholique de Louvain 
CORE DISCUSSION PAPER 2007/8

\title{
The problem of non-renewable energy resources in the production of physical capital $^{*}$
}

\author{
Agustín Pérez - Barahona ${ }^{\dagger}$ \\ CORE, Université catholique de Louvain
}

31st January 2007

\begin{abstract}
This paper studies the possibilities of technical progress to deal with the growth limit problem imposed by the usage of non-renewable energy resources, when physical capital production is relatively more energy-intensive than consumption. In particular, this work presents the conditions under which energy-saving technologies can sustain long-run growth, although energy is produced by means of non-renewable energy resources. The mechanism behind that is energy efficiency.
\end{abstract}

Keywords: Nonrenewable resources, Energy-saving technical progress, Economic growth.

Journal of Economic Literature: O30, O41, Q30, Q43

${ }^{*}$ I would like to thank Catarina Goulão, Katheline Schubert, and Raouf Boucekkine for their useful comments. I knowledge the financial support of the Chaire Lhoist Berghmans in Environmental Economics and Management (CORE). Any remaining errors are mine.

${ }^{\dagger}$ Corresponding author. CORE, Université catholique de Louvain, 34 voie du Roman Pays, B-1348, Louvain-la-Neuve (Belgium). Tel.: +32 10474352; fax: +32 10474301; email: perez@core.ucl.ac.be 


\section{Introduction}

Standard papers on non-renewable energy resources (see for instance, Dasgupta and Heal (1974, 1979), Stiglitz (1974), Sollow (1974), Hartwick (1989), and Smulders and Nooij (2003)) assume the same technology for both physical capital production and consumption (which implies that the energy intensity of both sectors is the same), as well as the existence of reasonable substitution possibilities between energy and physical capital. Moreover, this literature also claims that if energy is produced by means of non-renewable resources, physical capital accumulation could offset the constraints on production possibilities due to non-renewable energy resources (Dasguptan and Heal (1979)). Nevertheless, our paper argues that this explanation about physical capital accumulation as a solution to the problem of non-renewable energy resources is not totally satisfactory since there is empirical evidence showing that physical capital production is relatively more energy-intensive than consumption (Pérez-Barahona (2006)). Indeed, under this hypothesis, if energy were produced by means of non-renewable energy resources, this would limit growth through physical capital accumulation. Then, all solution based on rising physical capital accumulation can have dubious effectiveness to solve the trade-off between economic growth and the usage of non-renewable energy resources if one does not analyze the role of energy in physical capital accumulation, i.e., equipment good production. Following that idea, this paper shows that, if physical capital production is relatively more energy-intensive than consumption, technical progress (in particular, energy-saving technical progress) plays a central role to guarantee long-run growth. Indeed, we establish that if the growth rate of technical progress is high enough there is balanced growth path (BGP) with positive growth of all the endogenous variables. Otherwise, the economy decreases at constant rate, with all the endogenous variables converging to zero asymptotically. This result contrasts with the claim of Stiglitz (1974) and Dasgupta and Heal (1979). These authors argue that, even without technical progress, capital accumulation can offset the constraint on production possibilities due to non-renewable energy resources. However, our paper shows that the economy decreases (converging to zero asymptotically) if there is no growth of technical progress.

This paper emphasizes the role of energy-saving technical progress as a solution to solve the trade-off between economic growth and the usage of non-renewable energy resources, such as fossil fuels. Boucekkine and Pommeret (2004) point out the importance of energy-saving technologies. The 
idea of this kind of technologies is energy efficiency. According to various studies (COM (2005)), the European Union (EU) could save at least $20 \%$ of its present energy consumption (EUR 60 billion per year, or the present combined energy consumption of Germany and Finland) by improving energyefficiency.

In order to illustrate the ideas previously presented, this paper builds a general equilibrium model, based on Hartwick (1989), with three sectors: final good, equipment good, and extraction sector, where physical capital production is relatively more energy-intensive than consumption. In this model, the equipment good sector produces physical capital by means of a technology defined over two inputs: energy and investment, where the energy is directly obtained from a given stock of a non-renewable energy resource. This work presents the conditions under which technical progress (in particular, energy-saving technical progress) can guarantee positive long-run growth.

The paper is organized as follows. Section 2 introduces the model, with a description of each sector. The optimal solution of this economy is presented in Section 3, together with the interpretation of the main results of the paper. Finally, Section 4 concludes.

\section{The model}

Following Hartwick (1989), let us consider an economy with three sectors where the energy is obtained by means of non-renewable energy resources, and the population is constant ${ }^{1}$. The final good sector produces a nondurable good with AK technology, where physical capital is the only input. As usual, the final good is assigned to consumption or investment. The equipment sector produces physical capital (equipment good) be means of a technology defined over two inputs: energy and investment. Finally, the extraction sector directly produces energy by extracting a non-renewable resource from a given stock.

\footnotetext{
${ }^{1}$ See Stigliz (1974) for an analysis of the growth possibilities open to an economy with non-renewable energy resources and an exponential growing labour force.
} 


\section{$2.1 \quad$ Final good sector}

The final good sector produces a non-durable good $Y(t)$ by means of the following $A K$ technology:

$$
Y(t)=A(t) K(t),
$$

where $A(t)$ is the (exogenous) disembodied technical progress, and $K(t)$ represents the equipment good, which is the only input to produce the final good. Moreover, the final good is used either to consume, $C(t)$, or to invest in physical capital, $I(t)$, verifying the budget constraint of the economy

$$
Y(t)=C(t)+I(t) .
$$

As the introduction points out, the standard literature on non-renewable energy resources considers energy as an additional input in the production of the final good ${ }^{2}$, assuming the same technology for both physical capital production and consumption. Then, if energy is produced by means of nonrenewable energy resources, there is (a priori) a limit to economic growth due to the stock restrictions of this kind of natural resources. In general, the solution to this problem (without replacement of non-renewable resources by renewable ones) is based on greater physical capital accumulation. However, this literature does not study the case of having different technologies for physical capital production and consumption, which is empirically supported (Pérez-Barahona (2006)). Indeed, if physical capital production is relatively more energy-intensive than consumption, non-renewable resources can limit growth through the equipment production. In fact, the aim of this paper is to study the effects of this hypothesis on the long-run growth of the economy. For simplicity reasons, an AK technology is assumed, considering energy as input for equipment production, i.e., physical capital production is relatively more energy-intensive than consumption.

\footnotetext{
${ }^{2}$ In general,

$$
Y(t)=F[K(t), R(t)] .
$$

Examples:

$$
\begin{aligned}
Y(t)= & {\left[\alpha_{1} K(t)^{(\sigma-1) / \sigma}+\alpha_{2} R(t)^{(\sigma-1) / \sigma}\right]^{\sigma /(\sigma-1)} \mathrm{CES}, } \\
& Y(t)=K(t)^{\alpha_{1}} R(t)^{\alpha_{2}} \text { Cobb-Douglas. }
\end{aligned}
$$
}




\subsection{Equipment good sector}

The equipment good sector produces physical capital by means of a technology with two inputs. On the one hand, the equipment good sector takes the fraction of final good devoted to equipment production, i.e., $I(t)$. And on the other, the equipment production needs energy, $R(t)$, which is directly produced by the extraction sector. The technology for equipment production is represented by the following Cobb-Douglas function:

$$
K(t)=[\theta(t) R(t)]^{\alpha} I(t)^{1-\alpha}, \text { with } 0<\alpha<0,
$$

where $\alpha$ is the share of non-renewable energy resource in equipment production, and $\theta(t)$ denotes the embodied energy-saving technical progress. In this paper, technical progress is considered as exogenous variable.

At this point, two observations are needed. First, this model considers physical capital as an intermediate good (equipment good). Indeed, it is assumed total depreciation of physical capital for each period. This allows us to regard $K(t)$ as a flow variable instead of a stock, getting an AK configuration, which has no dynamical transition. However, Pérez-Barahona (2006) eliminates this simplification assuming $K(t)$ as a durable good (stock variable). This entails technical difficulties ${ }^{3}$ and dynamical transition. Nevertheless, both models essentially have the same behavior along the BGP. Then, since the aim of this paper is to study the conditions under which technical progress can sustain long-run growth, $K(t)$ is considered here as a flow variable for simplicity reasons.

Second, equation (3) assumes substitutability between energy and investment. However, there is a very well known debate about substitutability vs. complementarity. Indeed, if one considers the idea of a minimum energy requirement to use a machine, the assumption of complementarity should be chosen (see Pérez-Barahona and Zou (2006a,b)). Nevertheless, taking the argument of Dasgupta and Heal (1979), if $I(t)$ is interpreted as final good service providing a certain (minimum) energy flow, one can keep the substitutability assumption.

\footnotetext{
${ }^{3}$ Pérez-Barahona (2006) deals with an optimal control problem with mixed constraints and two states variables: capital accumulation and stock of non-renewable resource. He provides a full analytical characterization of both short and long-run dynamics applying the technique of Special Functions representation.
} 


\subsection{Extraction sector}

The energy is directly produced by extracting a non-renewable energy resource $R(t)$ from a given homogeneous stock $S(t)$. As Dasgupta and Heal (1974), and Hartwick (1989), it is assumed costless extraction ${ }^{4}$. The evolution of this resource stock is described by the expression

$$
R(t)=-\dot{S}(t), \text { where } S(0) \text { is given. }
$$

Since one can not extract more than the available stock, the following restriction should be included

$$
S(t) \geq 0
$$

\subsection{Central planner solution}

The central planner (optimal solution) maximizes the instantaneous utility function of the representative household:

$$
\max W=\int_{0}^{\infty} \ln [C(t)] \exp (-\rho t) d t, \text { with } \rho>0,
$$

subject to equations (1)-(5), where $\rho$ is the time preference parameter (it is assumed to be a positive discount factor).

\section{Equilibrium}

This section presents the central planner solution, providing a full analytical characterization of the equilibrium of this economy. In the following, we solve the optimal control problem involved by this model. Moreover, the corresponding dynamical system is analyzed, providing the interpretation of the results.

\footnotetext{
${ }^{4}$ According to Dasgupta and Heal (1974), the extraction cost do not introduce any great problem if one assumes any non-convexities. Indeed, one can easily introduce extraction cost, $E C(t)$, by modifying the budget constraint of the economy:

$$
Y(t)=C(t)+I(t)+E C(R, S) \text {, where } \partial E C / \partial R>0 \text { and } \partial E C / \partial S \leq 0 .
$$
}




\subsection{Optimal control problem}

We can easily rewrite the central planner problem as an optimal control problem with mixed constraints:

$$
\max \int_{0}^{\infty} \ln \left[A(t) \theta(t)^{\alpha} R(t)^{\alpha} I(t)^{1-\alpha}-I(t)\right] \exp (-\rho t) d t
$$

subject to:

$$
\begin{gathered}
\dot{S}(t)=-R(t), \\
S(t) \geq 0,
\end{gathered}
$$

with $0<\alpha<1, \rho>0$, and $S(0)$ given,

where $S(t)$ is the state variable, $I(t)$ and $R(t)$ are the control variables, and $A(t)$ and $\theta(t)$ are exogenous functions.

Following Sydsæter et al. (1999, pages 109-110), the Lagrangian associated with this problem is

$$
\mathcal{L}(\bullet)=\ln \left[A(t) \theta(t)^{\alpha} R(t)^{\alpha} I(t)^{1-\alpha}-I(t)\right] \exp (-\rho t)-\lambda(t) R(t)+q(t) S(t),
$$

where $\lambda(t)$ and $q(t)$ are the Lagrangian multipliers. The corresponding first order conditions (FOC) are:

$$
\begin{gathered}
\frac{\partial \mathcal{L}}{\partial R(t)}=0 ; \frac{\partial \mathcal{L}}{\partial I(t)}=0 ; \\
\frac{\partial \mathcal{L}}{\partial S(t)}=-\dot{\lambda}(t) ; \\
q(t) \geq 0(=0 \text { if } S(t)>0) ; \\
\lim _{t \rightarrow \infty} \lambda(t) S(t)=0(\text { Transversality condition }) .
\end{gathered}
$$

The FOC for $R(t), I(t)$, and $S(t)$, yield, respectively,

$$
\begin{gathered}
\frac{A(t) \theta(t)^{\alpha} \alpha \frac{1}{R(t)}\left(\frac{R(t)}{I(t)}\right)^{\alpha}}{A(t) \theta(t)^{\alpha}\left(\frac{R(t)}{I(t)}\right)^{\alpha}-1} \exp (-\rho t)=\lambda(t)+q(t), \\
\frac{R(t)}{I(t)}=\left[A(t) \theta(t)^{\alpha}(1-\alpha)\right]^{-\frac{1}{\alpha}}, \\
q(t)=-\dot{\lambda}(t) .
\end{gathered}
$$


Since the non-renewable energy resource is assumed to be essential input, it is not optimal to completely deplete the stock $S(t)$ in a finite $t$ (see Hartwick (1989)). Therefore, $S(t)>0$ for all $t$, which implies that $q(t)=0$ for all $t$. Then, from equation (8), one concludes that the shadow price of the non-renewable resource is constant for all $t$, i.e., $\lambda(t)=\lambda$.

Notice that, since $\lambda(t)=\lambda$ for all $t$, the transversality condition implies that the stock of non-renewable energy resource should be depleted asymptotically, i.e.,

$$
\lim _{t \rightarrow \infty} S(t)=0 .
$$

\subsection{Dynamical system}

Taking the FOC, the equilibrium of this economy is characterized by the following dynamical system:

Proposition 1. The optimal solution of this economy is a path

$$
\{R(t), I(t), K(t), Y(t), C(t), S(t)\}
$$

and a constant $\lambda$ that satisfy the following conditions for all $t$ :

1)

$$
\frac{A(t) \theta(t)^{\alpha} \alpha \frac{1}{R(t)}\left(\frac{R(t)}{I(t)}\right)^{\alpha}}{A(t) \theta(t)^{\alpha}\left(\frac{R(t)}{I(t)}\right)^{\alpha}-1} \exp (-\rho t)=\lambda
$$

2) equations (1)-(4), (7) and (9);

where $A(t)$ and $\theta(t)$ are exogenous functions.

Proposition 1 provides a dynamical system of 7 equations and 7 unknowns, which describes the equilibrium of this economy (optimal solution) for all $t$. Notice that $\lambda$ is the shadow price of the non-renewable resource.

\subsection{Optimal solution}

Solving the dynamical system of Proposition 1, one obtains the optimal solution paths for $\{R(t), I(t), K(t), Y(t), C(t), S(t)\}$, and the constant $\lambda$. Following Sollow (1974), it is assumed $A(t)=\bar{A} \cdot \exp \left(\gamma_{a} t\right)$ and $\theta(t)=\bar{\theta} \cdot \exp \left(\gamma_{\theta} t\right)$, where $\bar{A}>0, \bar{\theta}>0, \gamma_{A} \geq 0$, and $\gamma_{\theta} \geq 0$. Then, Proposition 2 establishes 
the optimal solution of this economy:

Proposition 2. For a given $S(0)>0, \rho>0,0<\alpha<1, \bar{A}>0, \bar{\theta}>0$, $\gamma_{A} \geq 0$, and $\gamma_{\theta} \geq 0$, the equilibrium of the economy in every time $t$ is given by

$$
\begin{gathered}
R(t)=\rho S(0) \exp (-\rho t), \\
S(t)=S(0) \exp (-\rho t), \\
I(t)=\rho S(0) \bar{\theta}[\bar{A}(1-\alpha)]^{\frac{1}{\alpha}} \exp \left\{\left(\frac{1}{\alpha} \gamma_{A}+\gamma_{\theta}-\rho\right) t\right\}, \\
K(t)=\rho S(0) \bar{\theta}[\bar{A}(1-\alpha)]^{\frac{1-\alpha}{\alpha}} \exp \left\{\left(\frac{1-\alpha}{\alpha} \gamma_{A}+\gamma_{\theta}-\rho\right) t\right\}, \\
Y(t)=\rho S(0) \bar{\theta} \bar{A}^{\frac{1}{\alpha}}(1-\alpha)^{\frac{1-\alpha}{\alpha}} \exp \left\{\left(\frac{1}{\alpha} \gamma_{A}+\gamma_{\theta}-\rho\right) t\right\}, \\
C(t)=\rho S(0) \bar{\theta} \frac{\alpha}{1-\alpha}[\bar{A}(1-\alpha)]^{\frac{1}{\alpha}} \exp \left\{\left(\frac{1}{\alpha} \gamma_{A}+\gamma_{\theta}-\rho\right) t\right\},
\end{gathered}
$$

and the shadow price of the stock of non-renewable resource is

$$
\lambda(t)=\lambda=\frac{1}{\rho S(0)} .
$$

Proof. The proof is provided in Appendix

\subsection{Interpretation of the results}

As general comment, one can observe that this economy is always in the BGP, which is defined as the situation where all the endogenous variables grow at constant rate, i.e., $x(t)=\bar{x} \cdot \exp \left(\gamma_{x} t\right)$, where $\gamma_{x}$ is the growth rate of the variable $x$. Indeed, Proposition 2 implies that

$$
\begin{gathered}
\gamma_{S}=\gamma_{R}=-\rho, \\
\gamma_{Y}=\gamma_{C}=\gamma_{I}=\frac{1}{\alpha} \gamma_{A}+\gamma_{\theta}-\rho, \\
\gamma_{K}=\frac{1-\alpha}{\alpha} \gamma_{A}+\gamma_{\theta}-\rho .
\end{gathered}
$$

The reason is the following. Section 2.2 points out the implications of assuming physical capital as a flow variable (total depreciation). Indeed, the 
assumption of physical capital as a non-durable good implies that the economy described in this paper has an AK representation. Then, this economy is always in the BGP, without dynamical transition. Furthermore, taking a similar set-up to this paper, Pérez-Barahona (2006) proves that the assumption of physical capital as a stock variable (durable good) adds dynamical transition with essentially identical long-run behavior as the economy with physical capital as flow variable ${ }^{5}$. Since this paper focuses on long-run growth, one can avoid some technical difficulties assuming physical capital as a non-durable good.

\subsubsection{Extraction sector}

Equation (18) implies that both the stock of non-renewable energy resource $S(t)$ and the extraction flow $R(t)$ decrease at the same constant rate. The explanation is the following. $\gamma_{S}=\gamma_{R}$ because energy is directly produced by extracting $R(t)$ from the stock $S(t)$ (see equation (4)). Moreover, the reason why both variables decrease at constant rate is because energy is produced by means of a non-renewable energy resource. Then, since the non-renewable energy resource is assumed to be essential input, the stock of the resource should be depleted asymptotically. The depletion rate is $\rho$, which is the time preference parameter of the household. Indeed, the greater $\rho$, the less important the future for the household. Then, if $\rho$ rises, the non-renewable resource is depleted faster, reducing the growth rates of the economy (see equations (19) and (20)):

$$
\frac{\partial \gamma_{i}}{\partial \rho}<0, \text { for all } i=Y, C, I, K, R, S .
$$

This effect is also reflected in the shadow price of the non-renewable energy resource (see equation (17)). The greater $\rho$, the lower shadow price of the resource. Then, the resource extraction increases ${ }^{6}$.

In addition, regarding to the levels, i.e., the initial values of the endogenous variables, Proposition 2 implies that the greater $\rho$, the greater the initial values, but with lower growth rates.

\footnotetext{
${ }^{5}$ As Pérez-Barahona (2006) observes, capital accumulation also implies that the growth rate of the technical progress affects the levels of our endogenous variables.

${ }^{6}$ Notice that a higher endowment of non-renewable energy resource $(S(0))$ also reduces the shadow price of the resource. Both $\rho$ and $S(0)$ increase the extraction level. However, only $\rho$ affects the depleting growth rate. This is because $\rho$ represents the time preference of the household.
} 


\subsubsection{Final and equipment good sectors}

From Proposition 2, one observes that technical progress (in particular, energy-saving technical progress) is a key element to guarantee long-run growth. Indeed, if there is no growth of technical progress, i.e., $\gamma_{A}=\gamma_{\theta}=0$, the economy decreases due to the negative effect of $\rho$ (see equations (19) and (20)). Furthermore, one can establish the conditions for technical progress to preserve positive growth:

Proposition 3. $\gamma_{K}>0$ if and only if $(1-\alpha) \gamma_{A}+\alpha \gamma_{\theta}>\alpha \rho$;

$\gamma_{Y}\left(=\gamma_{C}=\gamma_{I}\right)>0$ if and only if $\gamma_{A}+\alpha \gamma_{\theta}>\alpha \rho$.

Notice that, according to this model, the growth rate of physical capital $\gamma_{K}$ is lower than the growth rate of output $\gamma_{Y}\left(=\gamma_{C}=\gamma_{I}\right)$. Indeed, one can easily obtain that $\gamma_{K}=\gamma_{Y}-\gamma_{A}$. This is because the output incorporates the effect of the disembodied technical progress $A(t)$ (see equations (1) and $(3))^{7}$. Then, the condition for positive growth of all the endogenous variables of the model is presented in the following proposition:

Proposition 4. $\gamma_{K}>0$ and $\gamma_{Y}\left(=\gamma_{C}=\gamma_{I}\right)>0$ if and only if $(1-\alpha) \gamma_{A}+\alpha \gamma_{\theta}>\alpha \rho$.

Proposition 4 establishes that the growth rate of technical progress should be high enough to maintain positive growth. Otherwise, the economy decreases at constant rate, with all the endogenous variables converging to zero asymptotically. Moreover, from equations (19) and (20), it is clear that the higher the growth rate of technical progress, the higher the long-run growth rates of the economy ${ }^{8}$.

A simple quantitative evaluation can be done by applying equations (18)(20) and the previous condition. Taking an explicit target of GDP annual growth rate $\left(\gamma_{Y}\right)$, one can determine the minimum annual growth rate of energy-saving technical progress $\left(\gamma_{\theta}\right)$ compatible with that target. The empirical literature widely accepts a value for the time preference of household $(\rho)$ of $3 \%$, as well as an annual growth rate of disembodied technical progress $\left(\gamma_{A}\right)$ about 1\%. According to this model, for a target of $\gamma_{Y}=2 \%$ (which is a common target for developed countries), the annual depleting rate of the

\footnotetext{
${ }^{7}$ If $\gamma_{A}=0$ then $\gamma_{K}=\gamma_{Y}\left(=\gamma_{C}=\gamma_{I}\right)$.

${ }^{8}$ Notice that the levels of the endogenous variables are positively affected by the levels of technical progress (see Proposition 2).
} 
resource should be $3 \%$, i.e., $\gamma_{S}=\gamma_{R}=-3 \%$. Moreover, for given values of the share of energy resource in the production of equipment goods $(\alpha)$, the second row of Table 1 provides the compatible values of the annual growth rate of energy-saving technical progress $\left(\gamma_{\theta}\right)$.

Table 1

\begin{tabular}{|c|c|c|c|}
\hline$\alpha$ & 0.25 & 0.5 & 0.75 \\
\hline$\gamma_{\theta}$ & $1 \%$ & $3 \%$ & $3.7 \%$ \\
$\gamma_{Y}$ with $\gamma_{\theta}=0$ & $1 \%$ & $-1 \%$ & $-1.7 \%$ \\
$\gamma_{K}$ with $\gamma_{\theta}=0$ & $0 \%$ & $-2 \%$ & $-2.7 \%$ \\
\hline
\end{tabular}

The values of the second row can be compared with empirical estimations of $\gamma_{\theta}$. Azomahou et al. (2004) estimates an annual growth rate of energy-saving technical progress for the USA around 1.9\%, and $0.9 \%$ for France. According to this exercise, problems could arise if the share of non-renewable energy resource in equipment production $(\alpha)$ is high. Indeed, one can observe (see Table 1, second row) that the higher $\alpha$ the higher growth rate of energysaving technical progress $\left(\gamma_{\theta}\right)$ is required. This effect can be illustrated by the following two figures.

Figure 1

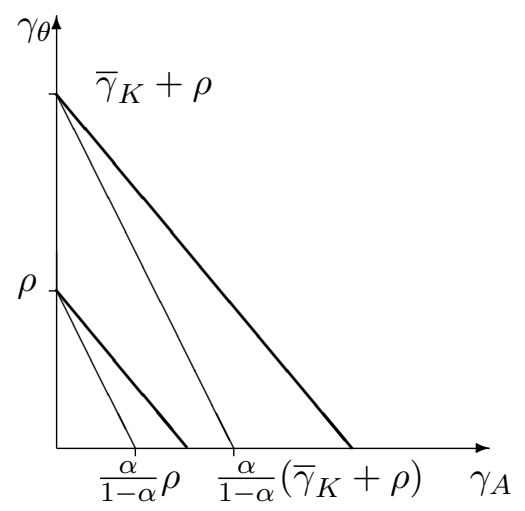

Figure 2

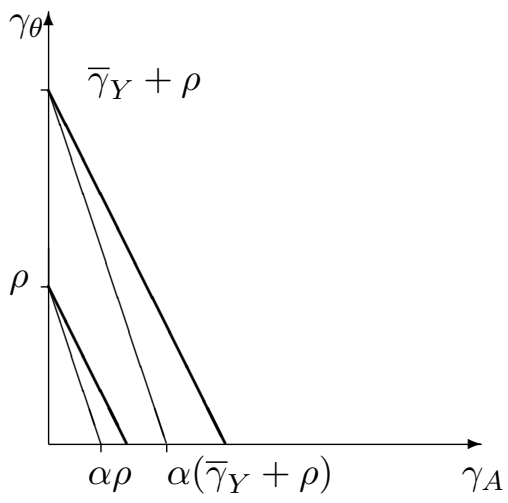

Figure 1 represents the set of pairs $\left(\gamma_{\theta}, \gamma_{A}\right)$ that yields the same growth rate of physical capital ${ }^{9}$, i.e., level curves. In this model, the level curves for the growth rate of physical capital are parallel straight lines with negative

\footnotetext{
${ }^{9}$ From equation (20), for a fixed value of $\bar{\gamma}_{K}$, we can easily obtain the level curve $\gamma_{\theta}=\left(\bar{\gamma}_{K}+\rho\right)-\frac{1-\alpha}{\alpha} \gamma_{A}$. Notice that $\gamma_{\theta}=\rho-\frac{1-\alpha}{\alpha} \gamma_{A}$ is the level curve corresponding to $\bar{\gamma}_{K}=0$.
} 
slope $-\frac{1-\alpha}{\alpha}$, where the growth rate of physical capital $\left(\bar{\gamma}_{K}\right)$ increases as one moves to the top right-hand corner of the figure. If the share of non-renewable resources in equipment good production rises, the absolute value of the slope decreases. Then, the level curves become flatter (bold line). Hence, for a fixed growth rate of disembodied technical progress $\left(\gamma_{A}\right)$, the growth rate of energy-saving technical progress $\left(\gamma_{\theta}\right)$ should be higher in order to maintain a target of growth rate of physical capital. The reason is unambiguous. The greater the share of non-renewable resources in equipment good production, the greater required growth rate of energy-saving technical progress to ensure a target of growth rate of physical capital. Figure 2 replicates the same logic as Figure 1, but for the case of output growth rate. Indeed, the greater the share of non-renewable resources in equipment good production, the greater required growth rate of energy-saving technical progress to ensure a target of output growth rate.

Finally, Table 1 also illustrates how important is energy-saving technical progress to guarantee positive growth. Rows third and fourth provide, respectively, the growth rate of output and physical capital, when there is no growth of energy-saving technical progress (i.e., $\gamma_{\theta}=0$ ), but there is the disembodied one $\left(\gamma_{A}=1 \%\right)$. When $\alpha=0.25$, the growth rate of output is $1 \%$. However, there is no growth of physical capital $\left(\gamma_{K}=0 \%\right)$. Moreover, as $\alpha$ increases, both the growth rate of output and physical capital are negative. Nevertheless, as the second row illustrates, the economy can maintain a growth rate target (in this case, $\gamma_{Y}=2 \%$ ) opting for energy-saving technologies.

\subsubsection{Energy efficiency}

The previous section points out the role of technical progress to guarantee long-run growth. The mechanism behind that is energy efficiency: technical progress allows for a BGP with positive growth because it reduces energy intensity. Let us define energy intensity as the quantity of energy per unit of output, i.e., the ratio $R(t) / Y(t)^{10}$. Taking equations (12) and (15), one easily obtains the following proposition:

\footnotetext{
${ }^{10}$ There are two alternative definitions of energy intensity: $\frac{R(t)}{K(t)}$ and $\frac{R(t)}{I(t)}$.
} 
Proposition 5. For a given $\rho>0,0<\alpha<1, \bar{A}>0, \bar{\theta}>0, \gamma_{A} \geq 0$, and $\gamma_{\theta} \geq 0$, the energy intensity of the economy in every time $t$ is given by:

$$
\frac{R(t)}{Y(t)}=\frac{1}{\bar{\theta} A^{\frac{1}{\alpha}}(1-\alpha)^{\frac{1-\alpha}{\alpha}}} \exp \left\{-\left(\frac{1}{\alpha} \gamma_{A}+\gamma_{\theta}\right) t\right\} .
$$

From this proposition, we can conclude that the energy intensity decreases at the constant rate ${ }^{11}$

$$
\gamma_{\frac{R(t)}{Y(t)}}=-\left(\frac{1}{\alpha} \gamma_{A}+\gamma_{\theta}\right)
$$

Then, technical progress decreases energy intensity, which is consistent with empirical works, such as Azomahou et al. (2004). Indeed, the greater the growth rate of technical progress, the lower the growth rate of energy intensity. Furthermore, if technical progress does not grow, the energy intensity is constant and the economy does not overcome the growth limit problem of non-renewable energy resources (indeed, in this case, output decreases at the rate $\rho$ ).

\section{Concluding remarks}

This paper studied the possibilities of technical progress to deal with the growth limit problem imposed by the usage of non-renewable energy resources, when physical capital production is relatively more energy-intensive than consumption. In order to illustrate the problem, we considered a general equilibrium model with three sectors: final good, equipment good, and extraction sector. In this model, the equipment good sector produces physical capital by means of a technology defined over two inputs: energy and investment, where the energy is directly obtained from a given stock of a nonrenewable energy resource. This work presented the conditions under which technical progress (in particular, energy-saving technical progress) guarantees positive long-run growth. Indeed, Proposition 4 established that the growth rate of technical progress should be high enough to maintain a positive growth of all the endogenous variables. Otherwise, the economy decreases at constant rate, with all the endogenous variables converging to zero

\footnotetext{
${ }^{11}$ Notice that, following the alternative definitions, energy intensity decreases at constant rate too. Indeed,

$$
\gamma_{\frac{R(t)}{K(t)}}=-\left(\frac{1-\alpha}{\alpha} \gamma_{A}+\gamma_{\theta}\right) ; \quad \gamma_{\frac{R(t)}{I(t)}}=-\left(\frac{1}{\alpha} \gamma_{A}+\gamma_{\theta}\right)
$$
}


asymptotically. The mechanism behind that was energy efficiency (Proposition 5): technical progress reduces energy intensity, allowing for a BGP with positive growth. The optimal solution (central planner solution) was considered. However, one can easily obtain the same results for the decentralized economy, which is a typical outcome when no externality is considered in the economy.

This paper entails several limitations. The main one is pointed out in Section 2.2. This model considers physical capital as a non-durable good, i.e., flow variable. However, physical capital is usually considered as a durable good, i.e., stock variable. The assumption of physical capital as a flow variable allow us to deal with an optimal control problem with only one state variable (the stock of non-renewable energy resources) instead of two state variables (the previous one, and the stock of physical capital). Indeed, this model has AK representation, which has no dynamical transition (see Proposition 2). The simplification of physical capital as a flow variable is equivalent to consider physical capital as a stock variable, with total depreciation for each period. However, this is not a very realistic assumption because one important characteristic of physical capital is its partial depreciation, i.e., physical capital is a durable good. Then, one should examine the consistency of the results presented in this paper considering energy as an input for physical capital accumulation, i.e., physical capital as a stock variable. As Section 2.2 also observes, this kind of analysis is done in Pérez-Barahona (2006), where physical capital is a durable good. This paper entails technical difficulties and dynamical transition. However, the behavior of this model along the BGP is essentially identical to our model with physical capital as a non-durable good. If one focuses on the behavior along the BGP, the simplification of physical capital as a non-durable good provides a simpler set-up, without dynamical transition.

Two possible extensions of the model could be done. First, the quantitative evaluation presented in Section 3.4.2 points out the convenience for an accurate estimate of the share of energy resources in the equipment good sector $(\alpha)$. As Table 1 notices, the share of energy resources in the equipment good production has important role to determine the growth rate of technical progress to guarantee a target of long-run growth. Since the standard literature on non-renewable energy resources assumes the same technology for both physical capital production and consumption, there are only estimations of this share for final good production. Finally, as second extension, one should observe that technical progress is assumed to be exogenous 
variable. However, technical progress (in particular energy-saving technical progress) is a variable decided endogenously by the economy. Due to the tractability of the set-up considered in this paper, one can incorporate endogenous technical progress by adding a R\&D sector for the energy-saving technical progress. Following Aghion and Howitt (1992) and Grossman and Helpman (1991a,b), one can model energy-saving technical progress with improvements in the "quality" of investment goods. Doing that, one can study the capacity of different policies (such as fossil fuel taxes or R\&D subsidies) to induce greater investment in energy-saving technologies, and their effects on the short and long-run growth of the economy.

\section{References}

Aghion P. and Howitt P., 1992. A Model of Growth through Creative Destruction. Econometrica 60(2): 323-351.

Azomahou Th., Boucekkine R. and Nguyen Van P., 2004. Energy Consumption, Tecnical Progress and Economic Policy, Mimeo, June.

Boucekkine R., Pommeret A., 2004. Energy saving technical progress and optimal capital stock: the role of embodiment. Economic Modelling 21, 429-444.

COM, 2005. Doing more with less. Green Papers. Official Documents. European Union. 265, June.

Dasgupta P.S. and Heal G.M., 1974. The Optimal Depletion of Exhaustible Resources. Review of Economic Studies, (Special Number), 3-28.

Dasgupta P.S. and Heal G.M., 1979. Economic Theory and Exhaustible Resources. James Nisbet and Cambridge University Press.

Grossman G.H. and Helpman E., 1991a. Quality Ladders in the Theory of Growth. Review of Economic Studies, vol. 58, no. 1, January.

Grossman G.H. and Helpman E., 1991b. Quality Ladders and Product Cycles, Quarterly journal of Economics, vol. 106, no. 425, May.

Hartwick J.M., 1989. Non- renewable Resources: Extraction Programs and Markets. London: Harwood Academic.

Pérez-Barahona A., 2006. Capital accumulation and exhaustible energy resources: a Special Functions case. CORE Discussion Papers. Forthcoming. 
Pérez-Barahona A. and Zou B., 2006a. A comparative study of energy saving technical progress in a vintage capital model. Resource and Energy Economics 28, 181-191.

Pérez-Barahona A. and Zou B., 2006b. Energy saving technological progress in a vintage capital model. Economic Modelling of Climate Change and Energy Policies. Edward Elgar. Pages 166-179.

Smulders S., Michiel de Nooij, 2003. The impact of energy conservation on technology and economic growth, Resource and Energy Economics 25, 59-79.

Solow, Robert M, 1974. The Economics of Resources or the Resources of Economics, American Economic Review, American Economic Association, vol. $64(2), 1-14$.

Stiglitz J., 1974. Growth with Exhaustible Natural Resources: Efficient and Optimal Growth Paths, Review of Economic Studies, (Special Number), 123-137.

Sydsæter K., Strøm A. and Berck P, 2000. Economists' Mathematical Manual, Spinger.

\section{Appendix}

The strategy to solve the dynamical system of Proposition 1 is the following:

Step 1: Replacing equation (7) into equation (10), it yields $R(t)$.

Step 2: Replacing $R(t)$ into equation $(4), S(t)$ is obtained by solving a linear first-order differential equation.

Step 3: Knowing $S(t)$, the shadow price of the non-renewable resource $\lambda$ is determined by equation (9).

Step 4: Taking $R(t)$ into equation (7), one obtains $I(t)$.

Step 5: Applying $R(t)$ and $I(t)$ into equation $(3), K(t)$ is determined.

Step 4: Taking $K(t)$ into the final good technology (equation(1)), the output $Y(t)$ is easily obtained.

Step 6: Since $Y(t)$ and $I(t)$ have been determined, one gets $C(t)$ from the budget constraint of the economy (equation (2)). 
In the following, we apply the previous strategy to calculate the equilibrium.

Step 1 yields

$$
R(t)=\frac{1}{\lambda} \exp (-\rho t) .
$$

The linear first-order differential equation involved in Step 2 is

$$
R(t)=-\dot{S}(t) \text {, where } S(0) \text { is given. }
$$

The solution of this equation is given by the following expression:

$$
S(t)=S(0)-\int_{0}^{t} R(\tau) d \tau .
$$

Solving the integral, one easily obtains

$$
S(t)=S(0)+\frac{1}{\lambda} \frac{1}{\rho}(\exp (-\rho t)-1) .
$$

Taking the preceding expression for $S(t)$ into the equation (9), it yields equation (17) of Proposition 2

$$
\lambda=\frac{1}{\rho S(0)} .
$$

Replacing equation (17) into equations (A.1) and (A.2), one gets, respectively, the equations (12) and (13) of Proposition 2. Following Step 4 -6, one can easily complete the proof 
Département des Sciences Économiques de l'Université catholique de Louvain

Institut de Recherches Économiques et Sociales

Place Montesquieu, 3

1348 Louvain-la-Neuve, Belgique 